\title{
Swimming patterns of wild harbour porpoises Phocoena phocoena show detection and avoidance of gillnets at very long ranges
}

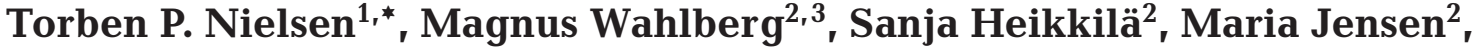 \\ Puk Sabinsky ${ }^{2}$, Torben Dabelsteen ${ }^{1}$ \\ ${ }^{1}$ Department of Biology, University of Copenhagen, Universitetsparken 15, 2100 Copenhagen East, Denmark \\ ${ }^{2}$ Marine Biological Research Laboratory, Institute of Biology, University of Southern Denmark, Hindsholmsvej 11, \\ 5300 Kerteminde, Denmark \\ ${ }^{3}$ Fjord \& Baelt, Margrethes Plads 1, 5300 Kerteminde, Denmark
}

\begin{abstract}
Harbour porpoises Phocoena phocoena are unintentionally caught in gillnets. Although the effectiveness of by-catch mitigation measures has been evaluated many times, only a few studies have investigated the behavioural patterns of the porpoises in relation to the presence of fishing nets. In this study, the reactions of wild harbour porpoises to a modified gillnet were visually observed. The porpoises responded to the net by avoiding it, with reactions being detectable at a distance of $>80 \mathrm{~m}$. The number of animals in the pods approaching the net did not affect the behaviour of individuals in relation to the net. These results strongly indicate that porpoises do not usually actively approach gillnets. The by-catch problem seems, therefore, to be caused by individual animals accidentally being caught, likely due to attention shifts or to auditory masking reducing their ability to detect the nets using echolocation.
\end{abstract}

KEY WORDS: Harbour porpoise $\cdot$ Phocoena phocoena $\cdot$ Swimming pattern $\cdot$ By-catch $\cdot$ Gillnet

\section{INTRODUCTION}

Many species of cetaceans are accidentally caught in fishing operations. Available data suggest that bycatch of the harbour porpoise Phocoena phocoena in Danish waters exceeds a sustainable level by far (Vinther 1999, Vinther \& Larsen 2004). There have been several scientific and legislative attempts both in Europe and North America to reduce the by-catch of this species (Larsen et al. 2002, 2007, Mooney et al. 2004). Despite these efforts, the reason why porpoises are by-caught remains unknown.

The harbour porpoise uses echolocation both for orientation and to find prey (Verfuss et al. 2005, 2009). Villadsgaard et al. (2007) showed that the source level of wild harbour porpoise echolocation clicks can be high enough for the animal to detect a gillnet at a distance of 13 to $26 \mathrm{~m}$. The detection distance may, however, be significantly reduced by factors such as variation in click intensity, increased background noise levels and the fact that the porpoise may not approach the net at a perpendicular angle (Kastelein et al. 2000, Mooney et al. 2004, 2007). Despite the fact that porpoises echolocate almost continuously, short periods of silence do occur (Akamatsu et al. 2007), during which porpoises may be caught in the net before becoming aware of it.

Only a few studies have investigated harbour porpoises' reactions to fishing nets or parts of nets such as ropes and float lines. One study showed that once captive harbour porpoises had been entangled a few times in nets placed in their pool, they learned to avoid them until the location of the nets was changed 
(Kastelein et al. 1995a). In an additional study, the swimming patterns of the animals were restricted when ropes were placed diagonally from surface to bottom in the pool (Kastelein et al. 1995b). These studies were both conducted in an extremely small tank and it is therefore difficult to extrapolate their findings to free-swimming animals. A field study (Koschinski et al. 2006) using acoustic data loggers to monitor porpoise behaviour compared the response to a regular fishing net with a net to which barium sulphate had been added to increase its acoustic reflectivity. Although the harbour porpoises seemed to respond to the barium sulphate net at slightly greater distances than the regular net, they also seemed to emit fewer echolocation clicks towards the treated net compared with the regular one (Koschinski et al. 2006). The interpretations of the results are, however, limited by various assumptions that must be made when deducing animal behaviour from acoustic logger data. These previous studies clearly show that more observations on harbour porpoise gillnet interactions in natural circumstances are needed to better understand the by-catch problem and how it should be mitigated.

Several hypotheses have been put forward to explain why harbour porpoises get caught in fishing nets. One states that the animals do not detect the net, or detect it too late to avoid it (Larsen et al. 2007, Mooney et al. 2007), another is that harbour porpoises do detect the net but do not consider it a hazard (Au \& Jones 1991, Mooney et al. 2007). In the present study we tested these hypotheses by observing visually how wild harbour porpoises responded to a modified gillnet deployed in their natural habitat.

\section{MATERIALS AND METHODS}

\section{Study area}

The study was conducted off the west coast of the peninsula Fyns Hoved, Denmark (55 37.2' N, $\left.10^{\circ} 35.3^{\prime} \mathrm{E}\right)$. The study area was approximately $400 \mathrm{~m}$ (north-south) along the coastline by $200 \mathrm{~m}$ (east-west). The area was marked with 3 anchored buoys. The maximum water depth was $5 \mathrm{~m}$ at mid tide. For the first few meters from the coastline the bottom was covered with small to medium-sized stones (diameter 3 to $30 \mathrm{~cm}$ ), and the following few metres were covered with seaweed of no more than $1 \mathrm{~m}$ in height. From a depth of 2 to $3 \mathrm{~m}$ the bottom was sandy with the occasional large seaweed- covered stone. The observation post was placed on a cliff $21 \mathrm{~m}$ above sea level halfway along the shore side of the study area.

\section{Observation protocol}

Due to varying weather conditions and varying numbers of porpoise encounters, we were able to conduct $60 \mathrm{~h}$ of observations with nets but only $23 \mathrm{~h}$ of control observations without nets between 18 July and 2 August 2008. An additional $20 \mathrm{~h}$ of net and $41 \mathrm{~h}$ of control observations were collected between 3 and 20 August 2009.

Observations were alternated between net and control observations following a random schedule. Both net and control observations could sometimes be conducted within the same day. Each net observation commenced with the net (standard hake net, $50 \mathrm{~m}$ long, $4 \mathrm{~m}$ high, mesh size $140 \mathrm{~mm}$ ) being deployed from a $12 \mathrm{ft}$ boat with an outboard engine. To decrease the risk of a harbour porpoise becoming caught in the net, all non-vertical filaments were cut. This modification meant that the net lost some of its structure, which resulted in occasional holes and some tangled sections. The net was placed in front of the observation post, with the closest end between 35 and $50 \mathrm{~m}$ off the coast, which meant that the exact position of the net within the study area varied due to wind and current. To allow quick access to the net, in case of a harbour porpoise becoming entangled, a $7 \mathrm{ft}$ dinghy was tied up close to the shore less than $40 \mathrm{~m}$ from the end of the net, with an $8 \mathrm{~mm}$ diameter line connecting the dinghy to the net. Controls were conducted in the same way as the net observations, excluding the use of a net. Whenever possible, the dinghy was deployed during control trials to make experimental and control conditions as similar as possible. This amounted to half and two-thirds of the total hours of observation in 2008 and 2009, respectively. Due to the small sample size, controls with and without the dinghy could not be tested separately. As the dinghy was used for more than half of the controls, any significant effect should be due to the presence of the nets and not the presence of the boat.

Harbour porpoise behaviour was visually observed by 3 observers using a theodolite (Geodimeter 468). One observer managed incoming data on the computer while the other 2 each observed one half of the study area. To avoid any bias due to observer effects, the observers alternated position and function every 30 min. Eight observers participated in 2008 and 14 
observers in 2009. Only 1 observer participated in both years.

Whenever a harbour porpoise entered the area, each surfacing was mapped with the theodolite. If a pod entered the study area, it was treated as 1 unit, and only 1 animal's surfacings were recorded. Positive identification of individual harbour porpoises was not possible, so tracking and following a single harbour porpoise in a pod was dependent on the skills of the observers. Each harbour porpoise unit (single harbour porpoise or pod, hereafter referred collectively to as a pod) was followed until it left the study area or was lost. During observations, pod size and the presence of calves was noted. To ensure sufficient data quality, observations were made between sunrise and sunset. As the probability of detecting harbour porpoises decreases with rising sea state (Teilmann 2003), observations were suspended whenever glare covered approximately one-third of the study area or whenever the sea state increased to more than 2. Data were collected during all tidal phases, both for control and experimental sessions.

\section{Data analysis}

Data analysis was conducted in Cyclops 3.1 realtime animal tracking software (http://cyclops-tracker. com) and ArcGis 9.2. Only surfacings inside the study area were used.

Analysis focused on 2 different aspects of the data. The first analysis compared the closest surfacing each pod made to the net and whether the pod size had any effect on this. In the controls (without a net) the location of a net, selected randomly from the actual net positions, was used as a reference point.

The second analysis investigated the distribution of harbour porpoises in different zones within the study area. Three different types of zones were defined, one originating at each of the individual nets (net zones), one based on the coastline (coastal zones) and one based on the observation post (observation post zones). The zones were all constructed following the same rules; they were $20 \mathrm{~m}$ wide and only the areas within the study area were included. As the coastal zone closest to the coast was mostly avoided by harbour porpoises and did not contribute with an even percentage to each of the zones based on the nets and on the observation post, it would have biased the data and was therefore excluded from the analysis of net and observation post zones. Harbour porpoise densities were calculated as the number of harbour porpoises per square meter per hour within each zone. Controls were obtained by applying each individual set of net zones, obtained during the net trials, to the total number of observations obtained during control trials.

\section{Statistical analysis}

All statistical analyses were performed in Graphpad InStat 3 and Matlab 6.5 using parametric or nonparametric tests depending on whether data met the requirements for parametric testing.

\section{RESULTS}

Data on the closest distances of harbour porpoise pods to the nets are given in Table 1, and surfacing locations are shown in Fig. 1. There was no significant difference between control and net conditions in 2008, whereas the 2009 data indicated, albeit not significantly so, an avoidance of the nets (Table 2). In 2008 no effect was found on the closest distance of approach as a function of pod size of 1,2 or 3 animals (Table 2). In 2009 it was only possible to test the difference between pods with 1 and 2 animals, and no difference was found (Table 2).

The distribution of porpoises as a function of the distance to the nets was statistically tested between years and treatments using a Kolmogorov-Smirnov (K-S) 2-sample test. The distribution of porpoises dif-

Table 1. Analysis of harbour porpoise Phocoena phocoena surfacings within the study area for 2008 and 2009. Mean \pm SE closest surfacing distance to the net is shown for all pods for net and control (i.e. no net) trials and for pods of 1, 2 and 3 animals. The number of observations of pods and total number of detected surfacings (values in parentheses) are also shown. nd: none detected

\begin{tabular}{|lccc|}
\hline & Year & $\begin{array}{c}\text { Closest } \\
\text { distance }(\mathrm{m})\end{array}$ & $\begin{array}{c}\text { No. of } \\
\text { observations }\end{array}$ \\
\hline All pods & & & \\
Net & 2008 & $66.1 \pm 5.8$ & $48(473)$ \\
& 2009 & $86.4 \pm 15$ & $17(120)$ \\
Control & 2008 & $56.8 \pm 8.5$ & $35(532)$ \\
& 2009 & $58.0 \pm 16$ & $57(430)$ \\
Pod size & & & \\
1 animal & 2008 & $68.8 \pm 7.7$ & 32 \\
& 2009 & $86.0 \pm 16$ & 7 \\
2 animals & 2008 & $57.5 \pm 9.0$ & 10 \\
& 2009 & $59.7 \pm 27$ & 7 \\
3 animals & 2008 & $76.0 \pm 17$ & 5 \\
& 2009 & nd & nd \\
\hline
\end{tabular}



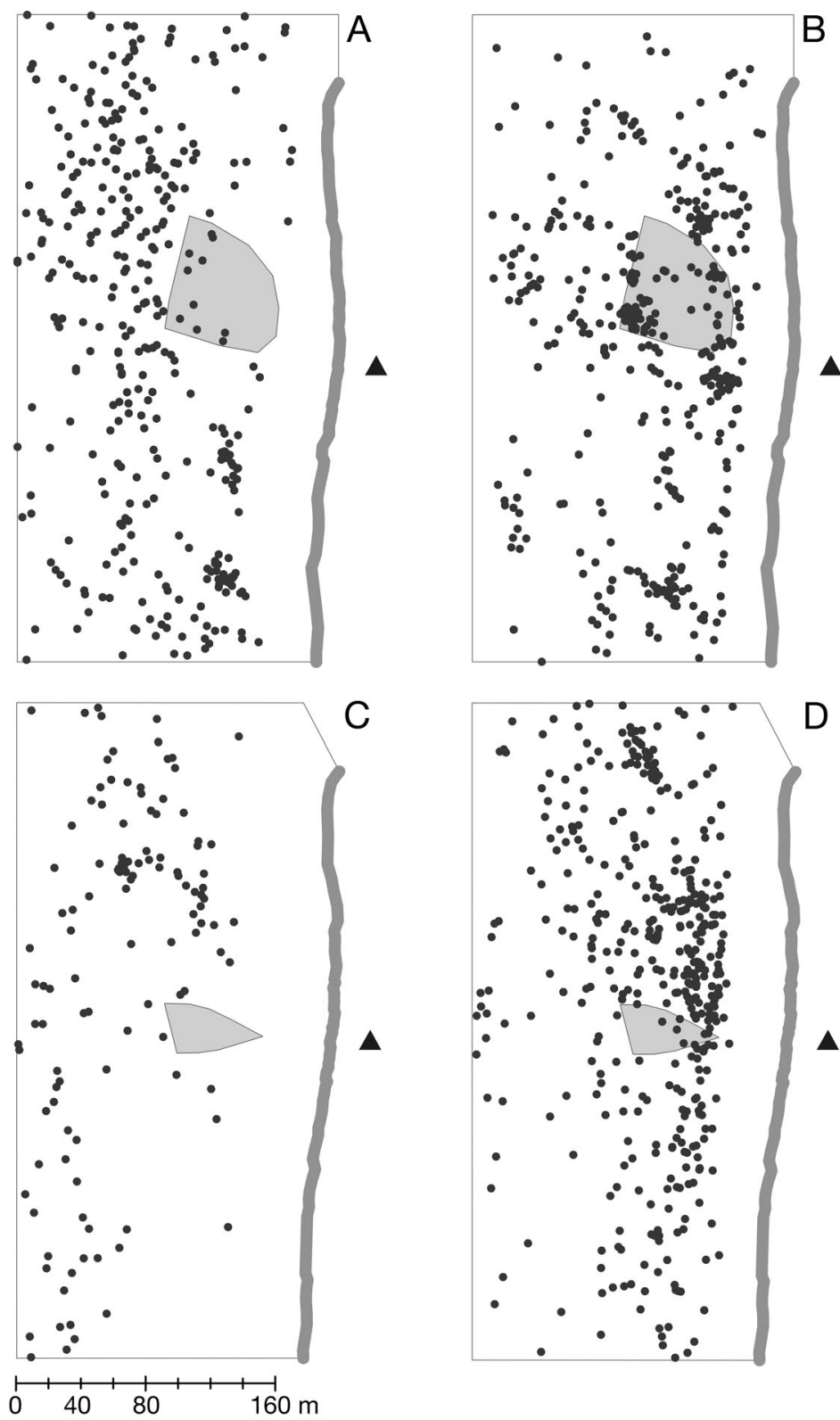

position from the net trials than further away (Table 2, Fig. 2), whereas no correlation between distance to the net and the number of surfacings was found for net observations (Table 2, Fig. 2). Visual inspection of Fig. 2 does, however, suggest that the number of surfacings and distance to the net is positively correlated at close distances. In 2008 a positive correlation was found in the range of 0 to $80 \mathrm{~m}$ (Table 2), while a positive correlation (albeit not significant) seems to be detectable to a distance of $100 \mathrm{~m}$ in 2009 (Table 2).

Analysis of the surfacings in different zones revealed a significant negative correlation between the number of surfacings observed during controls and the distances to the observer (Table 2, Fig. 3).

The data showed that harbour porpoises kept a greater distance from the coast when the net was in the water (Fig. 4). The distribution of porpoise surfacings varied significantly with the distance to the coast during net trials in 2008 and during controls in 2009 but not during controls in 2008 or net trials in 2009 (Table 2). Dunn's test revealed that in the net trials of 2008 the number of porpoises observed at ranges of 120, 140 and $160 \mathrm{~m}$ was significantly different from the number of observations at $20 \mathrm{~m}$, whereas in the control trials of 2009 there was a statistically significant difference between the following sets of distances: $20 \mathrm{~m}$ is significantly different from 60 and $80 \mathrm{~m} ; 60 \mathrm{~m}$ is different from 40, 160, 180 and $200 \mathrm{~m}$.

\section{DISCUSSION}

Fig. 1. Harbour porpoise Phocoena phocoena surfacings within the study area. Grey dots show locations of surfacings while the net was in the water in (A) 2008 and (C) 2009 and during controls in (B) 2008 and (D) 2009 shown relative to the coastline (bold grey line), the combined positions of all of the nets (light grey polygon) and the observation post ( $\mathbf{\Lambda})$

fered significantly between control and net experimental conditions in both years of data collection (Table 2). The distribution during controls in 2008 was not significantly different from 2009 (Table 2). The normalized distributions of porpoises during the observations with nets in 2008 were not significantly different from those in 2009 (Table 2).

For the control observations, significantly more surfacings were detected near a randomly chosen net the controls (Fig. 2), shows a clear avoidance effect of fishing nets in the study area. The same effect is strongly indicated by visual inspection of the species' swimming patterns around the net areas (Fig. 5). Using the same protocol in the 2 field seasons, the effect of the fishing net on the porpoise distribution proved to be very similar. The positive correlation between the density of harbour porpoise surfacings and the distance to the net indicated that 
Table 2. Statistical analysis of harbour porpoise Phocoena phocoena behaviour, shown as test used in each analysis, test statistic value with degrees of freedom and p-value. Significant values in bold. ANOVA: analysis of variance; K-S: Kolmogorov-Smirnov

\begin{tabular}{|c|c|c|c|}
\hline & Test & Statistic & $\mathrm{p}$ \\
\hline \multicolumn{4}{|c|}{ Closest distance to net, all pods } \\
\hline Net vs. control 2008 & $t$-test & $t_{1,81}=0.93$ & 0.36 \\
\hline Net vs. control 2009 & Mann-Whitney test & $U_{1,73}=340$ & 0.06 \\
\hline \multicolumn{4}{|c|}{ Distance as a function of pod size } \\
\hline 2008 & 1-way ANOVA & $F_{2,44}=0.43$ & 0.65 \\
\hline 2009 & $t$-test & $t_{2,12}=0.83$ & 0.43 \\
\hline \multicolumn{4}{|l|}{ Porpoise distribution } \\
\hline Net vs. control 2008 & K-S 2-sample test & $\operatorname{Dnn}_{7}=0.86$ & 0.004 \\
\hline Net vs. control 2009 & K-S 2-sample test & $\mathrm{Dnn}_{7}=1$ & 0.0004 \\
\hline Controls 2008 vs. 2009 & $\mathrm{~K}$-S 2-sample test & $\mathrm{Dnn}_{7}=0.57$ & 0.13 \\
\hline Net 2008 vs. 2009 & K-S 2-sample test & $\mathrm{Dnn}_{7}=0.57$ & 0.13 \\
\hline \multicolumn{4}{|c|}{ Distance to net or net position } \\
\hline Control 2008 & Linear regression & $F_{1,68}=230$ & $<0.0001$ \\
\hline Control 2009 & Linear regression & $F_{1,19}=190$ & $<0.0001$ \\
\hline Net 2008 & Linear regression & $F_{1,54}=0.44$ & 0.51 \\
\hline Net 2009 & Linear regression & $F_{1,19}=0.83$ & 0.37 \\
\hline Net 2008 0-80 m & Linear regression & $F_{1,30}=4.6$ & 0.04 \\
\hline Net 2009 0-100 m & Linear regression & $F_{1,13}=2.9$ & 0.11 \\
\hline \multicolumn{4}{|l|}{ Distance to observer } \\
\hline 2008 & Linear regression & $F_{1,89}=4.1$ & 0.045 \\
\hline 2009 & Linear regression & $F_{1,70}=9.3$ & 0.003 \\
\hline \multicolumn{4}{|l|}{ Distance to coast } \\
\hline Net 2008 & Kruskal-Wallis test & $\mathrm{Kw}_{9,71}=27$ & 0.0012 \\
\hline Net 2009 & Kruskal-Wallis test & $\mathrm{Kw}_{2,28}=12$ & 0.20 \\
\hline Control 2008 & Kruskal-Wallis test & $\mathrm{Kw}_{9,61}=10$ & 0.33 \\
\hline Control 2009 & Kruskal-Wallis test & $\mathrm{Kw}_{5,55}=37$ & $<0.0001$ \\
\hline
\end{tabular}

Harbour porpoises are thus able to detect gillnets at far greater distances than had previously been assumed based on what is known about their echolocation signals and hearing abilities (Mooney et al. 2004, Villadsgaard et al. 2007). Noise produced by fishing gear as a result of friction between ropes or splashing of buoys close to the surface may explain the large detection distance. In the water such noise may be audible at a distance of several tens of meters or more (Wahlberg et al. 2000). Also, the net used in the present study had all of the non-vertical filaments cut to avoid catching porpoises. This means that with time the net became tangled and formed larger lumps, which may have had a higher reflective capacity than a functional, normal gillnet. Finally, even a standard gillnet may be detectable at further distances than assumed, as the acoustic transmission loss in shallow waters from gillnets may be much smaller than the spherical spreading and point-target conditions assumed in previous studies (Mooney et al. 2004, Villadsgaard et al. 2007).

The negative correlation between the range over which the avoidance effect is detectable was at least $80 \mathrm{~m}$ in 2008 and even larger in 2009 (Fig. 2). porpoise density and distance to the net for control data in Fig. 2 is explained by the significant negative correlation between the density of harbour porpoises
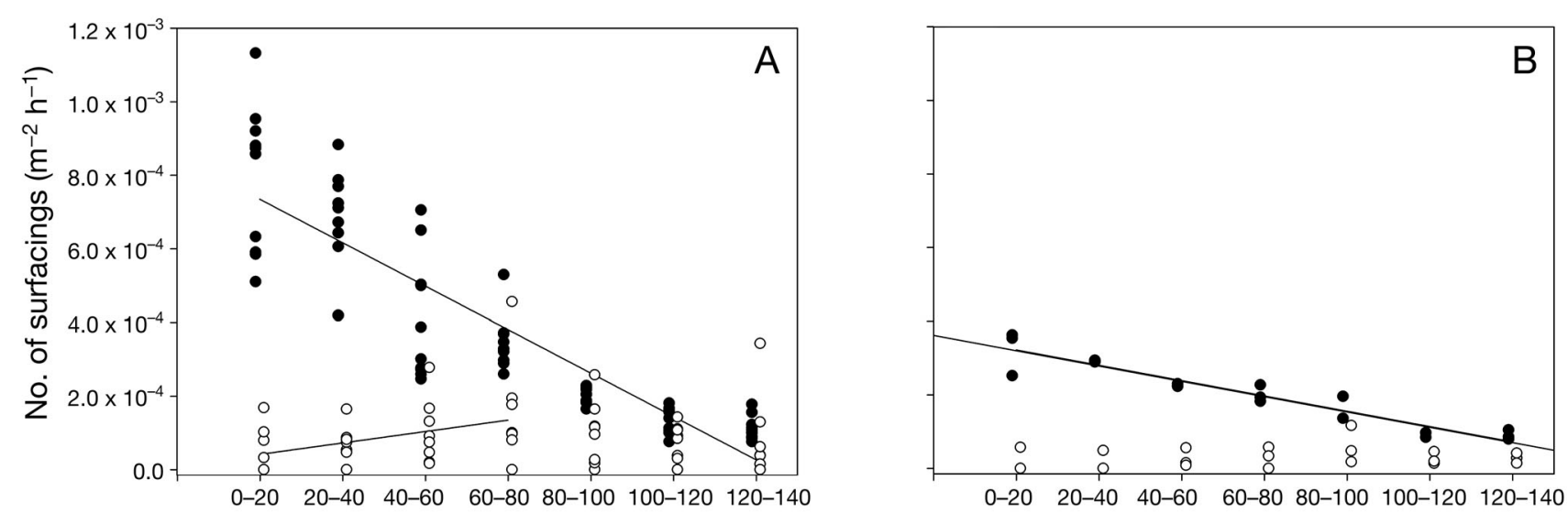

Distance to net $(\mathrm{m})$

Fig. 2. The number of detected harbour porpoise surfacings per $\mathrm{m}^{2}$ per hour of observation as a function of the range to a gillnet (०) compared to control trials (•) during (A) 2008 and (B) 2009. Each dot represents the average number of surfacings in a day. In the 2008 data, the linear regression has a correlation coefficient of -0.88 for the controls and 0.36 for the net data between 0 and $80 \mathrm{~m}$, and in 2009 the correlation coefficients were -0.95 for the controls and 0.43 for the net data between 0 and $100 \mathrm{~m}$ 


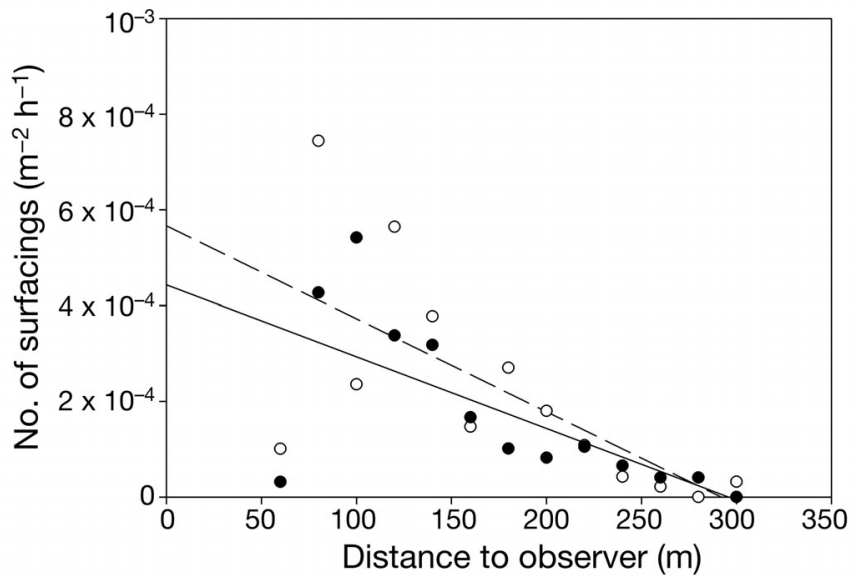

Fig. 3. The average number of harbour porpoise surfacings during controls (no net), measured as the number of surfacings per $\mathrm{m}^{2}$ per hour of observation, as a function of the distance to the observer. The correlation coefficient of the line is -0.21 in $2008(---\circ)$ and -0.34 in 2009 (一)
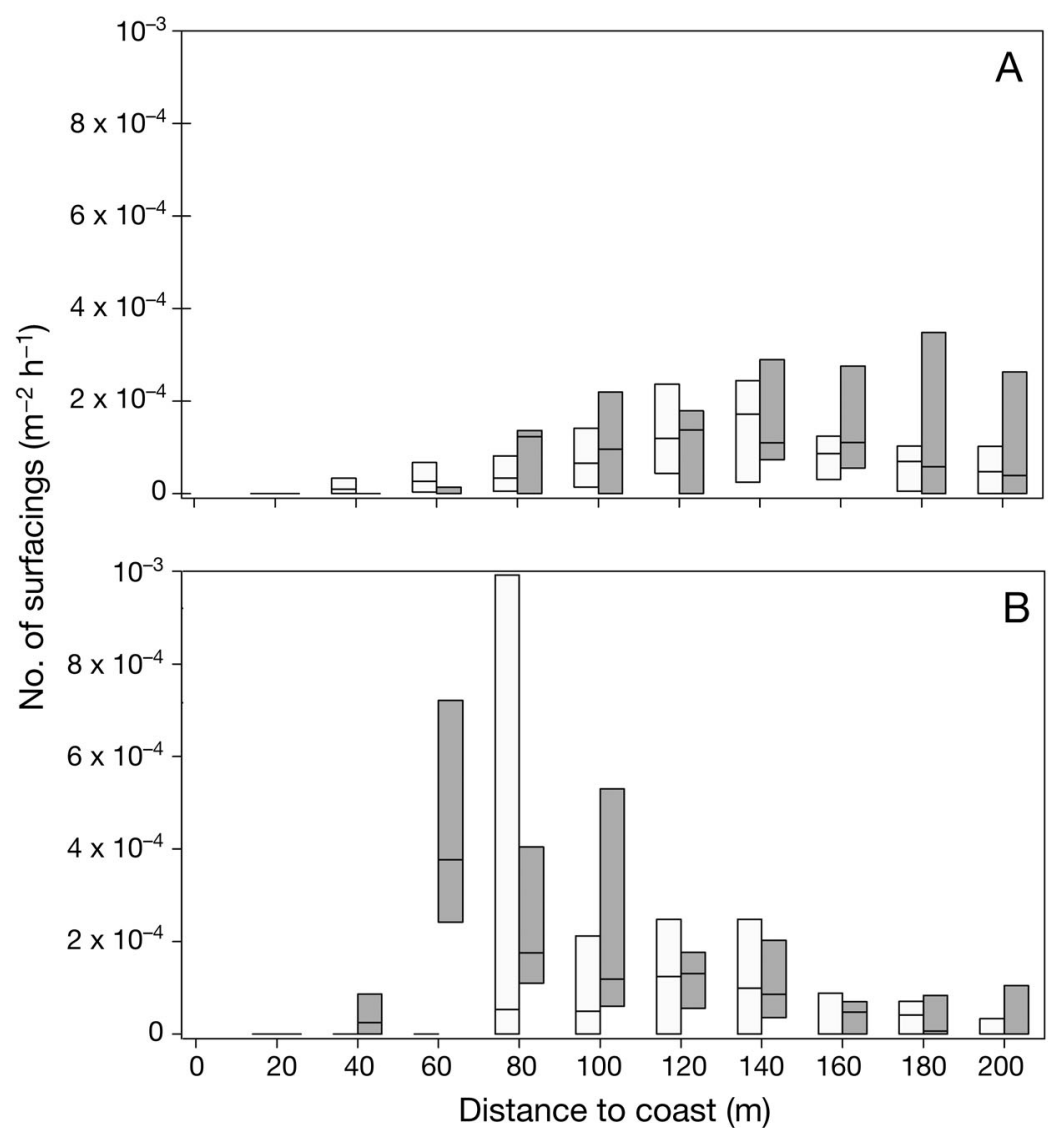

Fig. 4. The number of detected surfacings of harbour porpoises (per $\mathrm{m}^{2}$ per hour of observation) plotted against distance to the coast in $20 \mathrm{~m}$ intervals. Harbour porpoise density is shown as the upper and lower quartile and the median for data collected in 2008 ( $\square$ ) and 2009 ( $\square$ ). (A) Observations when the net was in place ( $N=8 d$ in 2008 and $3 d$ in 2009). (B) Observations during controls ( $\mathrm{N}=7 \mathrm{~d}$ in 2008 and $6 \mathrm{~d}$ in 2009). In the controls the median was identical to the lower quartile in 2008 at 160 and $200 \mathrm{~m}$ and in 2009 at $200 \mathrm{~m}$ spotted and the distance to the observer (Fig. 3). Only control data was used to establish this relationship to avoid any bias from observers paying extra attention to the region around the net. Similar effects of decreasing amounts of cetacean detections, as a function of the distance to the observer, have been shown in both airplane and ship surveys (Borchers et al. 1998, Hiby \& Lovell 1998).

The fact that the harbour porpoises keep a considerable distance from nets is further supported when looking at the relationship between harbour porpoise density and distance to the shore. Even though it was not statistically significant in all cases, the data indicated that when the net is in place, porpoises prefer to stay further away from the coast (Fig. 4). The fact that the presence of the nets shifted the harbour porpoises' swimming patterns and area preferences, even without the use of acoustic deterrent devices (pingers), might lead to animals being excluded from areas where fishing nets are frequently in use.

Despite their apparent ability to detect them, porpoises are still caught in gillnets in all areas where porpoises and fisheries share habitats (Read \& Gaskin 1988, Vinther \& Larsen 2004). It was previously thought that a major reason for porpoises becoming entangled is that they do not detect the nets before it is too late (Larsen et al. 2007, Mooney et al. 2007). In the present study, however, all harbour porpoises seemed to be well aware of the nets. The closest surfacing was observed at $7 \mathrm{~m}$ from the net and there was no sign of any physical contact between the harbour porpoises and the net. All these observations were gathered during good weather conditions. Increased background noise caused by waves or rain may reduce the harbour porpoises' chances of detecting a net, as compared to the observations made here. Apart from keeping their distance, the harbour porpoises did not show any interest in the net. Koschinski \& Culik (1997) reported that $16 \%$ of all harbour porpoises approaching a float line floated motionless at the surface while seemingly investigating it. In the present study, no such behaviour was observed.

Other hypotheses as to why porpoises become caught in fishing nets suggest 

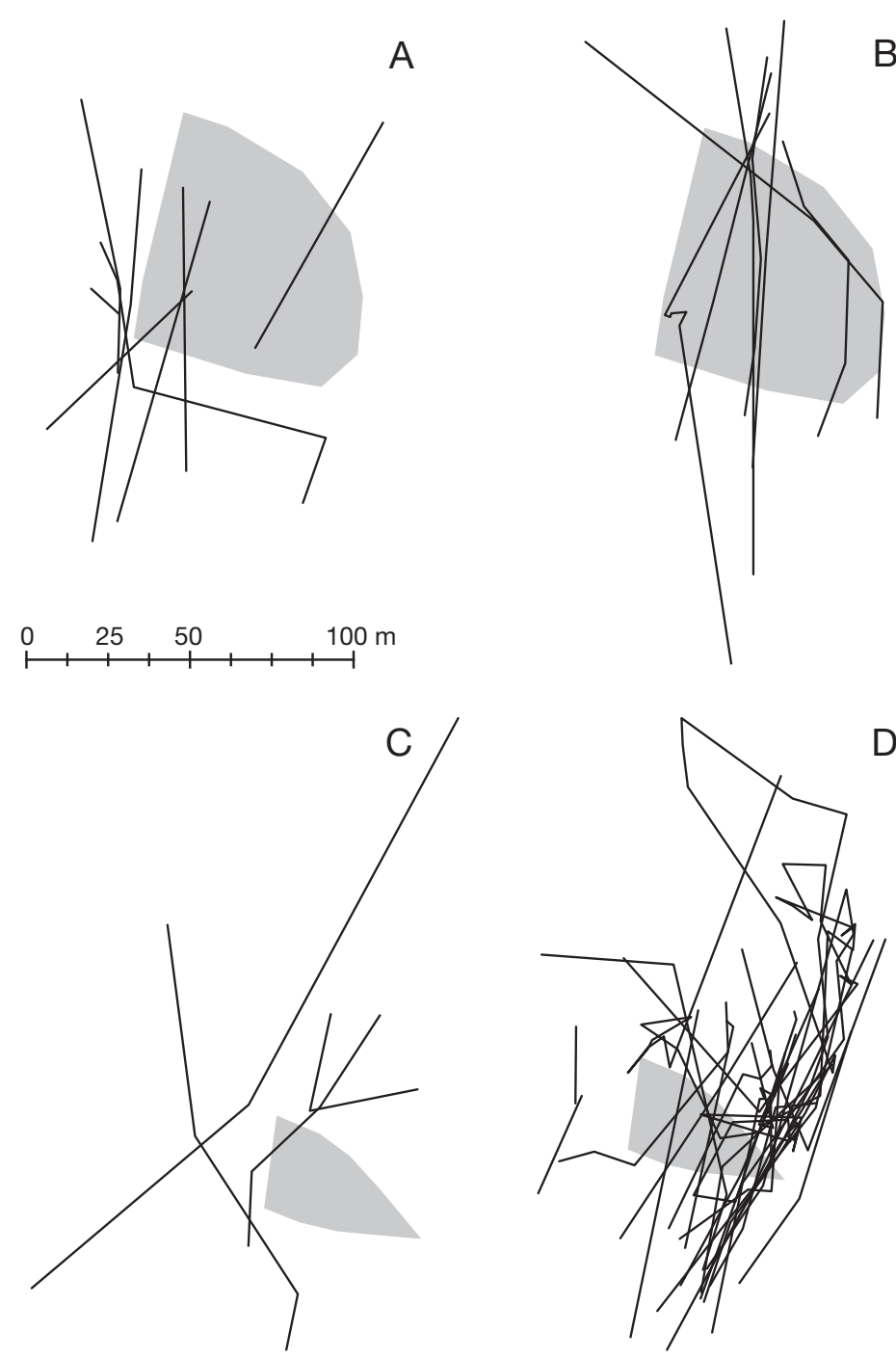

Fig. 5. The swimming patterns of the porpoise pods around the convex polygon (grey shading) defined by the combined positions of the nets. Tracks were generated by drawing lines between porpoise surfacings and included if pods surfaced within $20 \mathrm{~m}$ of the net polygon or if the track crossed the net polygon. Tracks of net trials in (A) 2008 and (C) 2009 and control trials in (B) 2008 and (D) 2009 are shown as no significant difference in approaching distance was found between pods of different sizes.

Fish in or around the net may either distract the harbour porpoises or echoes from the fish may mask the echoes of the net. As the net used here was modified not to catch harbour porpoises it did not catch any fish either. Pods of harbour porpoises were spotted fishing in the area, but this did not seem to make them more careless around the net or come closer to the net than any other pod. Apparently any foraging did not occur close enough to the net to allow for any interaction between net and porpoises.

The main conclusion of this study is that the harbour porpoises were clearly able to detect and avoid the gillnet. The slightly more tangled structure of the net used in the present study may have appeared as more of a barrier to the harbour porpoises than a regular gillnet; this barrier effect resulted in a remarkable relocation of the animals. However even with such an efficient barrier effect, some individuals still came within $10 \mathrm{~m}$ of the net. This means that some accidental by-catch may still occur as a consequence of attention shifts in individual animals or ambient noise masking of the echoes returning from the nets. To avoid accidental entanglements, active deterrent devices like pingers may be needed. Such devices have already proven very effective in preventing by-catch (Kraus et al. 1997, Carlström et al. 2002, Larsen et al. 2002). that harbour porpoises do detect the nets but do not pay attention to them. The animals may come into contact with the nets either because they are distracted by other harbour porpoises or prey, or simply because they do not regard the nets as a threat. In the present study, there were no signs of the harbour porpoises being careless around the net. A few pods crossed through the area where the nets were placed, but it was not possible to determine whether the harbour porpoises swam through holes in the net or if they found their way around it (Fig. 5). There was no sign of distraction on account of the other harbour porpoises either,
Acknowledgements. This study was funded by the European Strategic Fishery Fund (FIUF and EFF), the Danish Nature and Forest Agency, Fjord \& Belt, the Ministry of Food and Agriculture and the Danish Research Council for Nature and Universe (Framework grant no. 272-07-0477 to TD). We thank L. Delgado, K. Maj Ottosen (Fjord \& Belt), R. Nørrevang, C. P. Hansen, S. Johansen, B. Apel, A. Hansen, W. Albrechtslund, T. B. Jensen, K. R. Nielsen, L. Nielsen, P. Naundrup, E. R. Hansen, K. Jønck, L. Kjærulff and J. F. Tofte for their assistance during data collection, as well as L. Kindt-Larsen (DTU aqua), L. A. Kyhn (NERI), M. Amundin and his team from Kolmaarden Zoo, C. Krog (Krog Consult), C. Pedersen (Krog Consult) and C. King for their valuable comments and technical assistance. Finally, we thank the National Environmental Research Institute for their help with equipment and data collection. 


\section{LITERATURE CITED}

Akamatsu T, Teilmann J, Miller LA, Tougaard J and others (2007) Comparison of echolocation behaviour between coastal and riverine porpoises. Deep-Sea Res II 54:290-297

$\mathrm{Au}$ WWL, Jones L (1991) Acoustic reflectivity of nets: implications concerning incidental take of dolphins. Mar Mamm Sci 7:258-273

Borchers DL, Buckland ST, Goedhart PW, Clarke ED, Hedley SL (1998) Horvitz-Thompson estimators for doubleplatform line transect surveys. Biometrics 54:1221-1237

Carlström J, Berggren P, Dinnétz F, Börjesson P (2002) A field experiment using acoustic alarms (pingers) to reduce harbour porpoise by-catch in bottom-set gillnets. ICES J Mar Sci 59:816-824

Hiby L, Lovell P (1998) Using aircraft in tandem formation to estimate abundance of harbour porpoise. Biometrics 54: 1280-1289

Kastelein RA, de Haan D, Staal C, Nieuwstraten SH, Verboom WC (1995a) Entanglement of harbour porpoises (Phocoena phocoena) in fishing nets. In: Nachtigall PE, Lien J, Au WWL, Read AJ (eds) Harbour porpoises: laboratory studies to reduce bycatch. De Spil Publishers, Woerden, p 91-156

Kastelein RA, de Haan D, Staal C (1995b) Behaviour of harbour porpoises (Phocoena phocoena) in response to ropes. In: Nachtigall PE, Lien J, Au WWL, Read AJ (eds) Harbour porpoises: laboratory studies to reduce bycatch, De Spil Publishers, Woerden, p 69-90

Kastelein RA, Au WWL, de Haan D (2000) Detection distance of bottom-set gillnets by harbour porpoises (Phocoena phocoena) and bottlenose dolphins (Tursiops truncatus). Mar Environ Res 49:359-375

Koschinski S, Culik B (1997) Deterring harbour porpoises (Phocoena phocoena) from gillnets: observed reactions to passive reflectors and pingers. Rep Int Whal Comm 47: 659-668

Koschinski S, Culik BM, Trippel EA, Ginzkey L (2006) Behavioral reactions of free-ranging harbor porpoises Phocoena phocoena encountering standard nylon and $\mathrm{BaSO}_{4}$ mesh gillnets and warning sound. Mar Ecol Prog Ser 313:285-294

Editorial responsibility: Matthias Seaman, Oldendorf/Luhe, Germany
Kraus SD, Read AJ, Solow A, Baldwin K, Spradlin T, Anderson E, Williamson J (1997) Acoustic alarms reduce porpoise mortality. Nature 388:525

Larsen F, Vinther M, Krog C (2002) Use of pingers in the Danish North Sea wreck net fishery. Rep Int Whal Comm SC/54/SM3:1-8

> Larsen F, Eigaard OR, Tougaard J (2007) Reduction of harbour porpoise (Phocoena phocoena) bycatch by ironoxide gillnets. Fish Res 85:270-278

> Mooney TA, Nachtigall PE, Au WWL (2004) Target strength of a nylon monofilament and an acoustically enhanced gillnet: predictions of biosonar detection ranges. Aquat Mamm 30:220-226

Mooney TA, Au WWL, Nachtigall PE, Trippel EA (2007) Acoustic and stiffness properties of gillnets as they relate to small cetacean bycatch. ICES J Mar Sci 64: 1324-1332

> Read AJ, Gaskin DE (1988) Incidental catch of harbor porpoises by gill nets. J Wildl Manag 52:517-523

Teilmann J (2003) Influence of sea-state on density estimates of harbour porpoises (Phocoena phocoena). J Cetacean Res Manag 5:85-92

> Verfuß UK, Miller LA, Schnitzler HU (2005) Spatial orientation in echolocating harbour porpoises (Phocoena phocoena). J Exp Biol 208:3385-3394

Verfuß UK, Miller LA, Pilz PKD, Schnitzler HU (2009) Echolocation by two foraging harbour porpoises (Phocoena phocoena). J Exp Biol 212:823-834

Villadsgaard A, Wahlberg M, Tougaard J (2007) Echolocation signals of wild harbour porpoises, Phocoena phocoena. J Exp Biol 210:56-64

Vinther M (1999) Bycatches of harbour porpoises (Phocoena phocoena L.) in Danish set-net fisheries. J Cetacean Res Manag 1:123-135

Vinther M, Larsen F (2004) Updated estimates of harbour porpoise (Phocoena phocoena) bycatch in the Danish North Sea bottom-set gillnet fishery. J Cetacean Res Manag 6:19-24

Wahlberg M, Lunneryd SG, Bégout-Anras ML, Westerberg $H$ (2000). Whitefish leader net avoidance: possible roles of auditory cues. In: Moore A, Russell IC (eds) Advances in fish telemetry. CEFAS, Lowestoft, p 137-147

Submitted: June 28, 2011; Accepted: January 31, 2012

Proofs received from author(s): April 23, 2012 